\title{
Soil macrofaunal communities develop a habitat-specific trophic structure dependent on the degree of degradation of alpine wetlands
}

\author{
Juan Xue ${ }^{1}$, Xue Wei ${ }^{1}$, Haiyan $\mathrm{Guo}^{2}$, Changting Wang ${ }^{1}$, Pengfei $\mathrm{Wu}^{1 \text {,* }^{*}}$ \\ 1 Institute of Qinghai-Tibetan Plateau, Southwest Minzu University, Chengdu 610041, China \\ 2 Sichuan Climate Center, Chengdu 610071, China
}

\section{H I G H L I G H T S}

- Soil macrofaunal biomass varied in a nonlinear pattern during degradation.

- Detritivores responded more sensitively than other trophic groups to degradation.

- The dominant trophic group shifted from herbivores to detritivores during degradation.

- Macrofauna have stage-specific trophic structures during degradation.

- Soil properties outweigh vegetation on determining soil macrofaunal trophic structure.

\section{ARTICLE INFO}

Article history:

Received July 29, 2021

Revised September 12, 2021

Accepted September 29, 2021

Keywords:

Soil macrofauna

Trophic group

Zoige wetland

Degradation stage

Qinghai-Tibetan Plateau
GRAPHICAL ABSTRACT
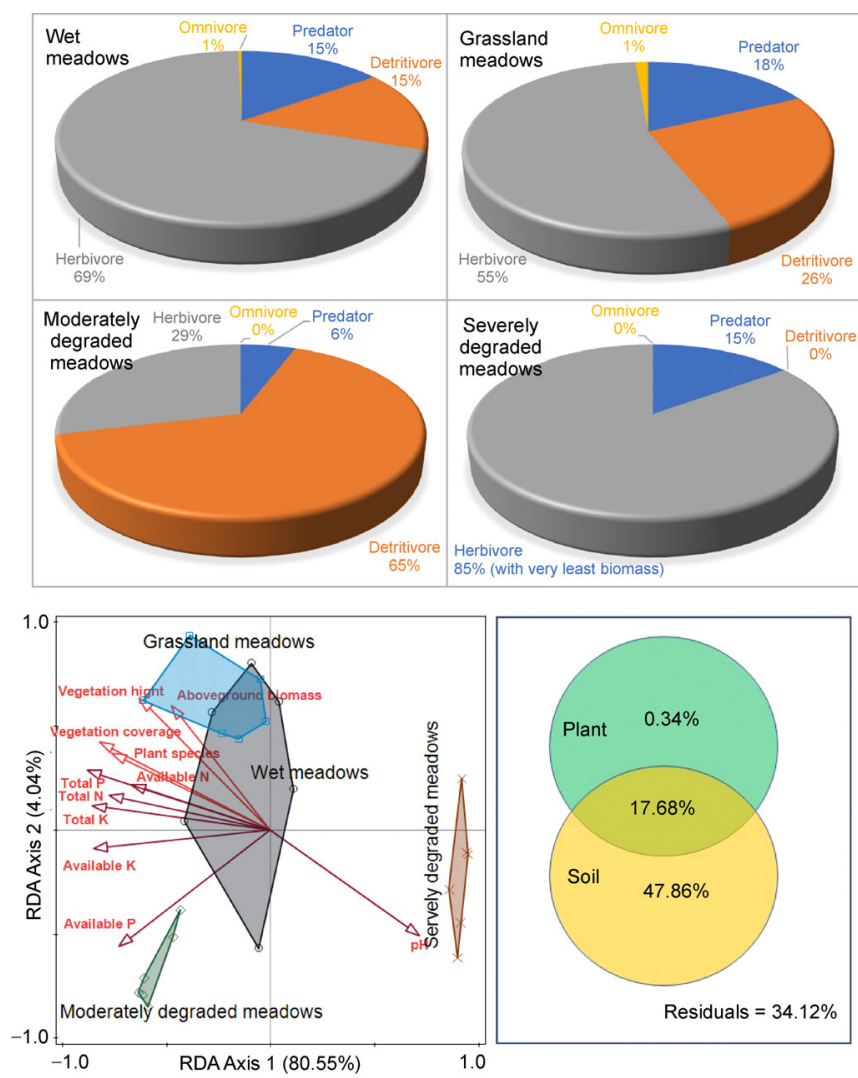

* Corresponding author

E-mail address: wupf@swun.edu.cn (P. Wu) 
The alpine wetlands in the Qinghai-Tibetan Plateau have degraded in recent decades. However, the response of the soil food web to the degradation is still unclear. Four habitats including a wet meadow (WM), a grassland meadow (GM), a moderately degraded meadow (MDM) and a severely degraded meadow (SDM) (sandy meadows) were selected along the degrees of degradation. The soil macrofaunal biomass and the environmental factors of vegetation and soil were investigated. The soil macrofaunal community biomass increased significantly from WM to MDM and decreased to a very small amount in SDM, with most taxa disappearing. The biomass of the trophic groups of detritivores, herbivores and predators exhibited similar responses to soil macrofaunal communities. The relative biomass of detritivores increased from WM to MDM, but herbivores responded in an opposite manner, resulting in the dominant trophic group and trophic structure varying progressively from WM to GM to MDM. Soil properties but not vegetation determined the changes in trophic groups and trophic structure. The results implied that the higher trophic levels (carnivores or omnivores) responded more sensitively than the lower trophic levels (herbivores) to alpine wetland degradation. Our results also suggested that soil macrofauna have a habitat-specific characteristic trophic structure and can be used as indicators of soil health conditions.

(C) Higher Education Press 2021

\section{Introduction}

Soil fauna play a key role in maintaining the structures and functions of grassland ecosystems (Bardgett and Cook, 1998; Bardgett and Chan, 1999; Bradford et al., 2002; Cole et al., 2006). The activities of soil fauna can regulate many important ecosystem processes of grasslands, such as decomposition and nutrient cycling (Ineson et al., 1982; Ingham et al., 1985; Bardgett and Chan, 1999; Bradford et al., 2002; Carrillo et al., 2011). However, an increasing number of studies have reported that soil fauna can also affect the plant community (Bardgett and Chan, 1999; Bradford et al., 2002; De Deyn et al., 2003) and soil properties (Bardgett and Putten, 2014). Moreover, changes in the trophic structure of soil fauna can influence decomposition processes (Cragg and Bardgett, 2001). The trophic structure of the soil fauna community determines the pathway of material cycling and energy utilization efficiency, reflecting the decomposition processes and health conditions of a given ecosystem (Setälä, 2002).

However, the trophic structure of soil fauna can be influenced by changes in plant communities (Wardle et al., 2003). A previous study also found that herbivore diversity was influenced by plant diversity (Siemann et al., 1999). Furthermore, lower trophic levels responded more strongly to changes in plant diversity than higher trophic levels (Scherber et al., 2010). Moreover, the trophic structure of soil fauna can be influenced by changes in soil properties. Previous research has found that an increase in soil fertility can lead to a high bacterivorous to fungivorous ratio in soil faunal communities (Stamou et al., 2005). Thus, different trophic groups respond in various ways to changes in the plant community and soil properties. Plant communities and soil properties are key factors influencing soil fauna in terrestrial ecosystems because they directly or indirectly determine the quantity and quality of food resources for soil fauna (Todd et al., 1992; Cole et al., 2006).
Although the trophic structure of soil fauna is an important aspect of the soil food web, research conducted on the trophic structure of soil fauna, especially macrofauna, is relatively rare (Koricheva et al., 2000; Doblas-Miranda et al., 2007). Moreover, most studies on trophic structure have only been conducted on abundances of individual trophic groups (Koricheva et al., 2000; Gunadi et al., 2002; Salamon et al., 2006; Scherber et al., 2010; Liu et al., 2011a; Ge et al., 2012; Zhou et al., 2017) and scarcely conducted on biomass (Scheu et al., 2003, 2010). There are substantial differences in individual biomass and/or body size among different taxa of soil fauna, especially macrofauna. Taxa with larger individual biomass or body size usually have relatively low individual abundances, and other taxa with smaller biomass or body size usually have large individual abundances. Therefore, conclusions about trophic structure drawn from individual abundances cannot always reflect actual belowground changes. However, body mass represents the amount of materials and energy contained by organisms and can reflect ecological functions to an important extent (Lam-Hoai et al., 1997). Therefore, it is necessary to reveal the changes in the trophic structure of soil macrofaunal communities by measuring biomass.

The alpine wetland is a widely distributed ecosystem on the Qinghai-Tibetan Plateau, which is called "the roof of the world" and "the third pole of the earth." The area of alpine wetland is approximately $4.9 \times 10^{4} \mathrm{~km}^{2}$ (Sun, 1996). However, alpine wetland degradation has become an important, widespread and growing problem on the Qinghai-Tibet Plateau under the influences of climate change (Zhang et al., 2007) and increasing livestock usage ( $\mathrm{Li}$ et al., 2008; Wang et al., 2008). Wet meadows, a primary stage of wetlands, have shifted into grassland meadows, and thereafter into moderately degraded meadows and ultimately severely degraded meadows (sandy meadows) on the Qinghai-Tibetan Plateau (He and Zhao, 1999). The dominant species have shifted, and the diversity and primary productivity have declined, 
according to degree of degradation, in recent decades (Wang et al., 2002). Soil physico-chemical properties have changed (Yang and Wang, 2001; Tian et al., 2005; Xiong et al., 2011; Gu et al., 2018), and soil biota diversity (Wu et al., 2015; Wu et al., 2017; Gu et al., 2018) has also diminished during the degradation process. However, the changes in the trophic structure of the soil food web in alpine wetland degradation are poorly understood (Wu et al., 2017). An understanding of the changes in the trophic structure of the soil faunal community is crucial for evaluating the functions and health of alpine wetlands.

We previously conducted a detailed sampling program on soil macrofauna in alpine wetlands at different degrees of degradation from 2009 to 2011, and analyses were conducted on the changes in taxonomic composition, abundances and diversity of the soil macrofaunal community (Wu et al., 2015) but not in trophic structure. The objectives of study presented in this report were to describe the changes in the trophic structure of soil macrofaunal communities by determining the trophic group responses based on biomass data during the degradation process of alpine wetlands. We hypothesized that (1) the biomass of soil macrofaunal communities would decrease continually with alpine wetland degradation due to a reduction in resource availability, (2) the lower trophic levels of soil macrofauna would respond more sensitively to the degradation of alpine wetlands than higher trophic levels, and (3) the trophic structure of soil macrofauna would be specific for a certain degree of degradation because different trophic groups responded in various ways to environmental changes.

\section{Materials and methods}

\subsection{Site description}

The research site is located in the Zoige wetland $\left(32^{\circ} 56^{\prime}-\right.$ $34^{\circ} 19^{\prime} \mathrm{N}, 102^{\circ} 08^{\prime}-103^{\circ} 39^{\prime} \mathrm{E}$ ), lying in a transitional zone between semi-humid alpine and semi-humid temperate climates. The elevation ranges from 3400 to $3800 \mathrm{~m}$. The mean annual temperature is $1^{\circ} \mathrm{C}$. The coldest monthly temperature is $-10.6^{\circ} \mathrm{C}$ in January, and the warmest monthly temperature is $10.8^{\circ} \mathrm{C}$ in July. The annual precipitation ranges from 600 to $800 \mathrm{~mm} ; 86 \%$ of the precipitation occurs between late April and mid-October. The temperature and precipitation during the sampling period (2009-2011) are shown as supplementary material in reference (Wu et al., 2015). The alpine wetlands in this region cover $6180 \mathrm{~km}^{2}$, which is $31.5 \%$ of the entire Zoige Plateau. Currently, four typical habitats exist in this area according to degradation degree: wet meadows (WM) (primary wetlands), grassland meadows (GM) (light degradation), moderately degraded meadows (MDM) (moderate degradation) and severely degraded meadows (SDM) (sandy meadows). The four habitats were used as pasture and grazed freely with no fertilizer or other managements. The dominant species, soil type and texture of each habitat were described as references (Wu et al., 2017; Wei and Wu, 2021), and the appearance characteristics could be referred to supplementary materials (Figs. S1-S4 and Table S1).

\subsection{Sampling design}

The methods of plot design, the size of macrofauna samples, macrofauna investigation and sampling month are presented in the reference (Wu et al., 2015; Wu et al., 2017). A total of 288 samples ( 4 habitats $\times 2$ plots $\times 3$ subplots $\times 4$ seasons $\times$ 3 years) were investigated during this study period from 2009 to 2011. All the macrofaunal individuals were identified to family according to the references (Zhong, 1990; Yin, 1998) and then classified in to four trophic groups of detritivores $(\mathrm{De})$, predators $(\mathrm{Pr})$, herbivores $(\mathrm{He})$ and omnivores $(\mathrm{Om})$ according to the references (Koricheva et al., 2000; Zhang et al., 2001; Doblas-Miranda et al., 2007; Huang and Zhang, 2008; Liao, 2009).

\subsection{Biomass measuring}

Regarding to the great differences in geography and environment between alpine wetlands and other ecosystems, we did not use the mass-length regression methods to calculate the biomass from other place (Scheu et al., 2003; Ehnes et al., 2011), but measured the biomass directly. For large and measurable individuals, the biomass was weighed individually using an electronic balance at milligram accuracy before and after drying to constant weight at $65^{\circ} \mathrm{C}$. For some abundant, small and immeasurable individuals that all belonged to the same family, samples were weighed together before and after drying to constant weight and the average biomass was calculated. For some rare, small and immeasurable individuals, the biomass was estimated by the dry weight ratio of other individuals belonged to the same family or order.

\subsection{Estimation of plant and soil parameters}

The measurements and results of environmental parameters of plant communities (including plant species (PS), vegetation coverage (VC), vegetation height $(\mathrm{VH})$, aboveground biomass $(\mathrm{AB})$ and belowground biomass (BB)) and soil properties (including soil organic matter (SOM), total $N(T N)$, total $K(T K)$, total $P(T P)$, available $N(A N)$, available $P(A P)$, available $K$ (AK) and $\mathrm{pH}$ value) of each habitats are presented in the references (Wu et al., 2015; Wu et al., 2017).

\subsection{Statistical analysis}

Before the following analysis, the biomass of each taxon, trophic group and macrofauna community collected from three $50 \mathrm{~cm} \times 50 \mathrm{~cm}$ subplots within the same plot and sampling month were averaged, and the relative biomass (\%) of each trophic group was also calculated to assess the relative role in 
community. The biomass data $\left(\mathrm{mg} \mathrm{m}^{-2}\right)$ for each trophic group was log-transformed to reduce the non-normality of data before analysis. A mixed model analysis was performed on the data sets of biomass $\left(\mathrm{mg} \mathrm{m}^{-2}\right)$ and relative biomass (\%) accumulated at different seasons to identify the differences between the habitats or years to understand the variations of community and each trophic group with the habitats and years used as fixed factors and plots used as random factor. Then, One-way ANOVA was performed on the biomass and relative biomass data sets accumulated throughout the years to evaluate the seasonal dynamics within each habitat. Multiple comparison tests (Tukey's) were performed on the means when the differences were significant. The tests were performed using IBM SPSS 22 for Windows.

The biomass of four trophic groups monitored in April, May, July and October were also averaged across three years for each plot to construct the data matrices. A multiple regression analysis (MRA) with collinearity diagnostics was applied to delete the most significant environmental parameters of plant and soil to avoid the multicollinearity, using IBM SPSS 22.0 for Windows. Redundancy analyses (RDA) was performed using CANOCO software 5.0 to qualitatively examine the relationships between the soil macrofaunal trophic structure and the environmental factors of plant and soil with a permutation test. Then, variation partition analysis (VPA) was performed using $\mathrm{R}$ (version 4.0.4) with the vegan package (v.2.5-7) to qualitatively determine the proportion of variation in the trophic structure explained by plant and soil factors. Furthermore, MRA with stepwise procedure was also used to quantitatively examine the relationships between the biomass of community/trophic groups and the measured parameters of plant and soil using IBM SPSS 22 for Windows.

\section{Results}

\subsection{Taxonomic composition and biomass of the soil macrofaunal community}

The 18 taxonomic orders and the biomass of soil macrofauna for the four habitats are shown in Table 1. The biomass varied significantly $(P<0.05)$ among habitats for polydesmida, dipteran larvae, haplotaxida, psocoptera, coleopteral larvae, lepidopteran, coleopteral adults, araneae and hymenopteran, but showed no significance $(P>0.05)$ for blattodea, symphyla, tubificida, homoptera, hemiptera, orthoptera, lithobiomorpha, mecoptera and opiliones.

The total biomass of the soil macrofaunal community increased gradually from WM (424.79 $\mathrm{mg} \mathrm{m}^{-2}$ ) to MDM (2994.54 $\mathrm{mg} \mathrm{m}^{-2}$ ) and decreased sharply to SDM (23.00 $\mathrm{mg} \mathrm{m}^{-2}$ ), with an average value of $1004.64 \mathrm{mg} \mathrm{m}^{-2}$ (Table 1). The total biomass varied among the three sampling years with no significance $(F=0.87, P>0.05)$ and increased from April to October $(F=3.06, P<0.05)$, but the pattern differed among habitats (Fig. 1).

\subsection{Responses of trophic groups to degradation}

The biomass increased from WM to MDM and decreased to SDM for detritivores, herbivores and predators (Fig. 2a, b and c) but increased from WM to GM and then decreased to MDM for omnivores (Fig. 2d). Significant differences in the biomass among habitats were recorded for the four trophic groups $(P<0.001)$, but no significance was detected between the sampling years and the interaction effects of habitat and year (Table 2). This implied that the degradation of alpine wetlands has a significant effect on the biomass of soil macrofaunal trophic groups.

The relative biomass of detritivores increased gradually from WM to MDM and decreased to zero in SDM (Fig. 3a), and the opposite tendency was observed for herbivores (Fig. 3b), resulting in the dominant trophic group shifting from herbivores in WM and GM to detritivores in MDM. The relative biomass of predators fluctuated among habitats (Fig. 3c), with omnivore biomass accounting for the lowest ratio among the four trophic groups (Fig. 3d). Significance was detected for habitat effects on the relative biomass of four trophic groups and for year effects on detritivores only (Table 2). The dynamics in relative biomass demonstrated that alpine wetland degradation has a stronger effect on detritivores than on herbivores and predators and alters the trophic structure.

3.3 Responses of trophic group seasonal dynamics to degradation

The seasonal dynamics in biomasses differed among habitats, and the pattern also varied with trophic groups (Fig. 4a, b, c and d). Significant differences among sampling months were detected for detritivores in GM and MDM, for herbivores and predators in GM and for omnivores in MDM (Table 3).

The relative biomass of detritivores increased from April to October in WM, GM and MDM, while an opposite tendency was observed for herbivores (Fig. $5 a$ and b). The relative biomass of predators and omnivores showed no obvious seasonal tendency in any habitat (Fig. $5 c$ and d). Significant differences in relative biomass among sampling months were only detected for detritivores in GM and omnivores in MDM (Table 3). The results showed that the responses of trophic structure to seasonal changes were relatively stable in WM and variable in $\mathrm{GM}$.

3.4 Environmental effects on soil macrofaunal trophic structure

The RDA results showed that axis 1 and axis 2 explained $80.55 \%$ and $4.04 \%$, respectively, of the variation in the trophic group data (Fig. 6a). The permutation tests showed that all axes combined explained a significant portion of the data variation $(F=7.60, P=0.002)$. TP, TK, AK and VC were the most important factors influencing the trophic structure 
Table 1 The biomass (mean \pm S.E., $\mathrm{mg} \mathrm{m}^{-2}$ ) of each trophic group and taxonomic order of soil macrofauna in alpine wetlands across 2009-2011 with a nonparametric test (Kruskal-Wallis test).

\begin{tabular}{|c|c|c|c|c|c|c|}
\hline $\begin{array}{l}\text { Taxonomic } \\
\text { order }\end{array}$ & $\begin{array}{l}\text { Wet } \\
\text { meadow }\end{array}$ & $\begin{array}{l}\text { Grassland } \\
\text { meadow }\end{array}$ & $\begin{array}{l}\text { Moderately degraded } \\
\text { meadow }\end{array}$ & $\begin{array}{l}\text { Severely } \\
\text { degraded } \\
\text { meadow }\end{array}$ & Chi-Square & $P$ \\
\hline Detritivores & $183.64 \pm 94.71 b$ & $331.93 \pm 120.52 b$ & $2347.19 \pm 506.68 a$ & & 8.59 & 0.035 \\
\hline Polydesmida & $156.62 \pm 94.67 \mathrm{~b}$ & & $1808.45 \pm 391.50 a$ & & 205.80 & $<0.001$ \\
\hline Diptera larvae & $26.81 \pm 9.25 b$ & $35.60 \pm 8.15 b$ & $79.67 \pm 11.84 a$ & & 101.52 & $<0.001$ \\
\hline Haplotaxida & & $264.38 \pm 113.03 a b$ & $455.27 \pm 247.09 a$ & & 26.94 & $<0.001$ \\
\hline Psocoptera & & & $0.95 \pm 0.6$ & & 167.98 & $<0.001$ \\
\hline Blattodea & $0.09 \pm 0.09$ & & & & 12.13 & 0.007 \\
\hline Symphyla & & $0.01 \pm 0.01$ & & & 3.00 & 0.392 \\
\hline Tubificida & $0.11 \pm 0.11$ & $31.93 \pm 20.01$ & $2.85 \pm 1.41$ & & 3.00 & 0.392 \\
\hline Herbivores & $194.52 \pm 23.36 b$ & $195.77 \pm 28.97 b$ & $462.36 \pm 57.12 a$ & $19.92 \pm 4.45 \mathrm{c}$ & 130.64 & $<0.001$ \\
\hline Coleoptera larvae & $183.58 \pm 23.39 b$ & $155.52 \pm 22.53 b$ & $403.92 \pm 54.1 \mathrm{a}$ & $14.88 \pm 4.02 \mathrm{c}$ & 131.76 & $<0.001$ \\
\hline Lepidoptera & $0.51 \pm 0.51 b$ & $21.62 \pm 5.92 \mathrm{ab}$ & $45.42 \pm 17.72 a$ & $0.73 \pm 0.58 b$ & 28.23 & $<0.001$ \\
\hline Homoptera & $9.11 \pm 3.62$ & $14.48 \pm 9.56$ & $10.64 \pm 4.95$ & $4.31 \pm 2.32$ & 2.56 & 0.464 \\
\hline Hemiptera & $0.15 \pm 0.11$ & $0.39 \pm 0.19$ & $0.88 \pm 0.46$ & & 5.64 & 0.131 \\
\hline Orthoptera & $1.18 \pm 0.84$ & $3.77 \pm 3.77$ & $1.49 \pm 1.33$ & & 5.00 & 0.172 \\
\hline Predators & $45.81 \pm 9.47 \mathrm{~b}$ & $45.72 \pm 9.20 \mathrm{~b}$ & $184.8 \pm 51.38 a$ & $3.08 \pm 1.68 b$ & 42.61 & $<0.001$ \\
\hline Coleoptera adult & $42.37 \pm 9.22 b$ & $45.11 \pm 9.2 b$ & $182.73 \pm 51.03 a$ & $3.08 \pm 1.68 b$ & 40.51 & $<0.001$ \\
\hline Araneae & $2.51 \pm 2.46$ & $0.09 \pm 0.09$ & $1.25 \pm 0.52$ & & 9.55 & 0.023 \\
\hline Lithobiomorpha & $0.14 \pm 0.11$ & $0.52 \pm 0.32$ & $0.24 \pm 0.16$ & & 4.54 & 0.209 \\
\hline Mecoptera & & & $0.59 \pm 0.59$ & & 3.00 & 0.392 \\
\hline Opiliones & $0.80 \pm 0.80$ & & & & 3.00 & 0.392 \\
\hline Omnivorous & $0.71 \pm 0.27 b$ & $2.81 \pm 0.81 a$ & $0.20 \pm 0.11 b$ & & 31.56 & $<0.001$ \\
\hline Hymenoptera (ants) & $0.71 \pm 0.27 b$ & $2.81 \pm 0.81 \mathrm{a}$ & $0.20 \pm 0.11 b$ & & 31.56 & $<0.001$ \\
\hline Total & $424.79 \pm 98.99 b$ & $576.22 \pm 143.74 b$ & $2994.54 \pm 525.28 a$ & $23.00 \pm 4.78 c$ & 185.81 & $<0.001$ \\
\hline
\end{tabular}

Note: Different lowercase letters in the same lines denote significant differences between the habitats $(P<0.05)($ Mann-Whitney $U$ test). The significant differences $(P<0.05)$ are shown in boldface.

(Fig. 6a). Moreover, the VPA results showed that a large part of the explained variation $(65.88 \%)$ was due to pure soil effects $(47.86 \%)$ and joint effects with plants (17.68\%), but pure plant factors only accounted for $0.34 \%$ (Fig. 6b). This analysis suggested that the trophic structure is mainly determined by changes in soil properties.

The MRA results (Table 4) showed that $A B$ correlated with the biomass and relative biomass of omnivores $(P<0.001)$, and $\mathrm{BB}$ correlated with the relative biomass of predators $(P<0.001)$. The AP contents correlated with the biomass of the community, detritivores and herbivores, as well as the relative biomass of detritivores $(P<0.01$ and $P<0.001)$. A significant correlation was detected between the AK contents and the biomass of herbivores and predators and the relative biomass of detritivores and herbivores $(P<0.05$ and $P<0.001$ ).

According to the RDA, VPN and MRA results, the soil properties were the determining factors for the trophic structure of the soil macrofaunal community during the alpine wetland degradation process.

\section{Discussion}

4.1 Degradation effects on the biomass of the soil macrofaunal community

The total biomass of soil macrofaunal communities was 

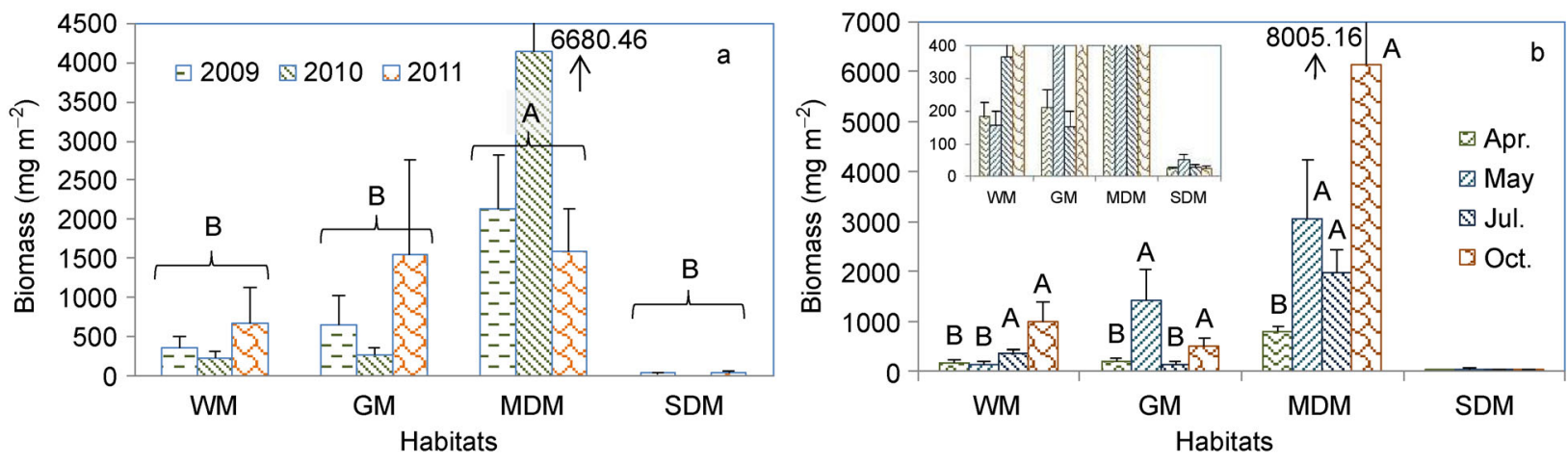

Fig. 1 Variations in the biomass of soil macrofaunal communities among the habitats for the sampling years (averaged over 4 months for each bar) (a) and months (averaged over 3 years for each bar) (b). The arrow and associated value represent the maximum value of stand error. The subfigure is magnified in Fig. $1 \mathrm{~b}$ to amplify the SDM. WM: wet meadow; GM: grassland meadow; MDM: moderately degraded meadow; and SDM: severely degraded meadow. Different capital letters on the bars denote significant differences between the habitats (Fig. 1a) and sampling months (Fig. 1b) (Tukey's test).
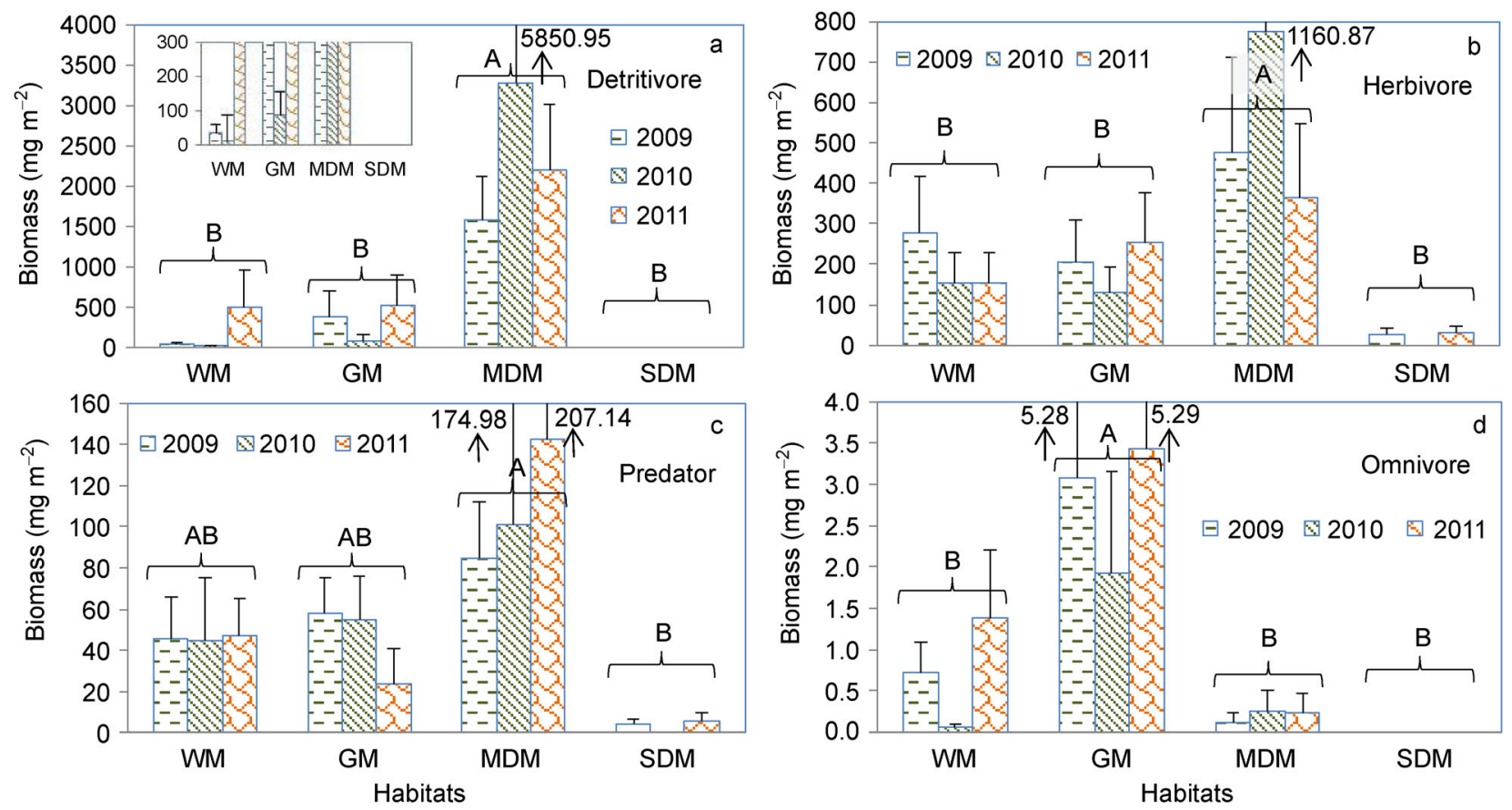

Fig. 2 Variations in the biomass of each trophic group among the habitats (averaged over 4 months for each bar) across three years. The subfigure is magnified in Fig. 2a to amplify WM. The arrow and associated value represent the maximum value of stand error. Different capital letters on the bars denote significant differences between the habitats (Tukey's test).

significantly higher in MDM than in the other habitats. The abundances and diversity of soil macrofaunal communities in this area exhibited similar tendencies (Wu et al., 2015). The changes in biomass, abundance and diversity indicated that the role of soil macrofauna was promoted by moderate degradation and weakened by severe degradation of alpine wetlands. The maximum abundance and richness of the soil macrofaunal community were also observed in the moderately desertified grassland in the Horqin sandy land region of Inner Mongolia, northern China (Liu et al., 2011b). The reason may be that the moderate degradation represents an intermediate disturbance, and this environment was suitable for most macrofauna. In our study area, most environmental factors in terms of plant and soil properties did not worsen in the MDM (Wu et al., 2015, 2017). Many studies have shown that the diversity of phytoplankton in marine environments (Sommer, 1995), macroinvertebrates in streams (Colin, 1997) and tree species in tropical rainforests (Molino and Sabatier, 2001) can be increased by intermediate disturbance. In our study, only a small amount of soil macrofaunal biomass was 

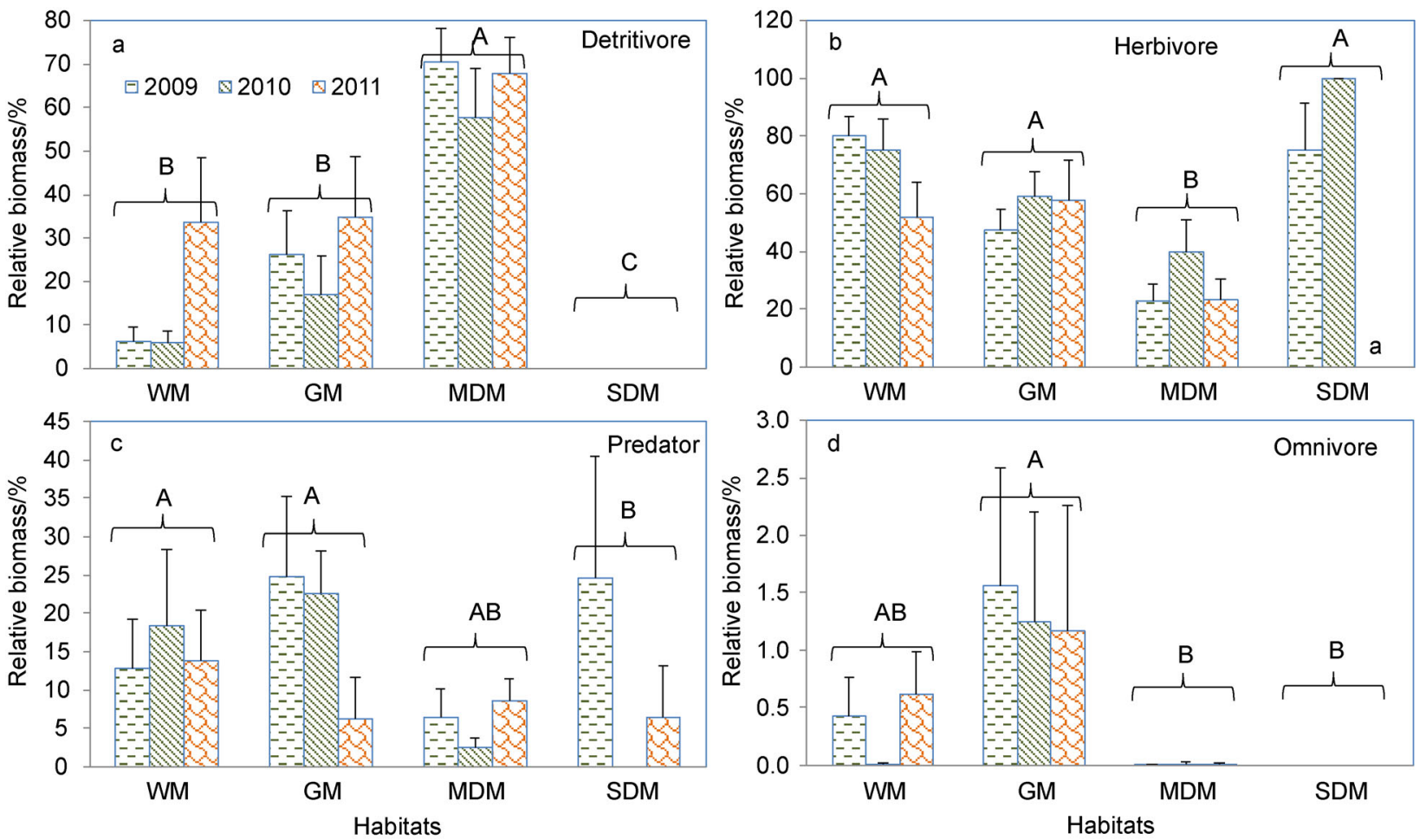

Fig. 3 Variations in the relative biomass of trophic groups among the habitats (averaged over 4 months for each bar) across three years. Different capital letters on the bars denote significant differences between the habitats $(P<0.05)$ (Tukey's test).

Table 2 Mixed model results for the effects of habitat, year and their interactions on the biomass and relative biomass of detritivores, herbivores, predators and omnivores in alpine wetlands on the Qinghai-Tibetan Plateau.

\begin{tabular}{|c|c|c|c|c|c|c|}
\hline \multicolumn{2}{|c|}{ Detritivore } & \multicolumn{2}{|c|}{ Herbivore } & \multicolumn{2}{|c|}{ Predator } & Omnivore \\
\hline$F$ & $p$ & $F$ & $p$ & $F$ & $p$ & $F$ \\
\hline
\end{tabular}

\begin{tabular}{lcccccccc}
\hline Biomass & & & & & & & & \\
Habitat & 12.92 & $<0.001$ & 15.30 & $<0.001$ & 7.49 & $\mathbf{0 . 0 0 1}$ & 7.54 & $\mathbf{0 . 0 0 1}$ \\
Year & 1.16 & 0.328 & 0.35 & 0.705 & 0.09 & 0.916 & 0.47 & 0.625 \\
Habitat $\times$ Year & 0.57 & 0.754 & 1.91 & 0.095 & 0.99 & 0.444 & 0.18 & 0.981 \\
Relative biomass & & & & & & & & \\
Habitat & 31.44 & $<0.001$ & 8.09 & $\mathbf{0 . 0 0 1}$ & 3.98 & $\mathbf{0 . 0 1 8}$ & 5.31 & $\mathbf{0 . 0 0 5}$ \\
Year & 4.03 & $\mathbf{0 . 0 2 4}$ & 1.59 & 0.214 & 2.48 & 0.094 & 0.38 & 0.683 \\
Habitat $\times$ Year & 0.95 & 0.471 & 1.25 & 0.296 & 2.92 & $\mathbf{0 . 0 1 6}$ & 0.54 & 0.776 \\
\hline
\end{tabular}

Note: Statistically significant $(P<0.05)$ results are shown in bold.

collected in SDM during the sampling years. A possible reason may be that some environmental factors in SDM exceed the tolerance ranges of most soil macrofauna, such that the habitat is no longer suitable (Hodkinson and Jackson, 2005). The dynamics in measurements of taxonomic trophic groups indicated that the decomposition and nutrient cycling through soil macrofaunal communities were strengthened by moderate degradation but suppressed significantly by severe degradation of alpine wetlands. In view of the nonlinear decreasing pattern of total biomass, our first hypothesis that the biomass of soil macrofaunal communities decreased continually with alpine wetland degradation was modified by the findings.

Of note, the mean value of the total biomass of soil macrofauna in alpine wetlands was $1004.64 \mathrm{mg} \mathrm{m}^{-2}$, ranging from $34.66 \mathrm{mg} \mathrm{m}^{-2}$ to $4143.49 \mathrm{mg} \mathrm{m}^{-2}$ (Fig. $1 \mathrm{a}$ and b). The total biomass was lower than that of arid shrubsteppe in the Mediterranean, where the mean biomass is $2.11 \mathrm{~g} \mathrm{~m}^{-2}$ (Doblas-Miranda et al., 2007), and the forests in north-eastern China, where the mean biomass ranges from $3.22 \mathrm{~g} \mathrm{~m}^{-2}$ to $16.36 \mathrm{~g} \mathrm{~m}^{-2}$ (Huang and Zhang, 2008). This lower biomass indicated that the roles of soil macrofauna were relatively 

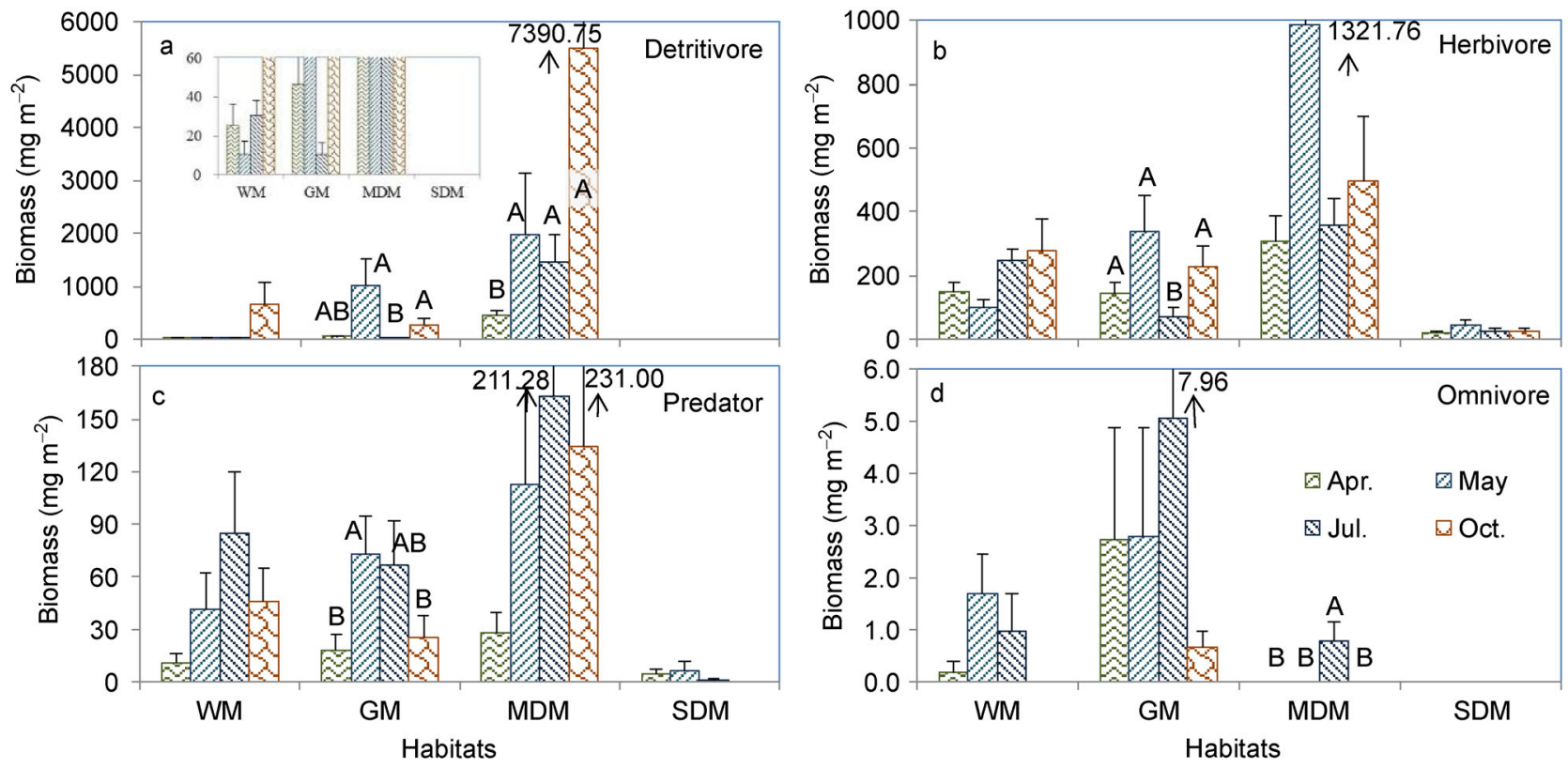

Fig. 4 The seasonal dynamics in biomass of detritivores, herbivores, predators and omnivores for the WM, GM, MDM and SDM of the Qinghai-Tibetan Plateau (averaged over 3 years for each bar). The arrow and associated value represent the maximum value of stand error. The subfigure in Fig. $4 a$ is the magnification for WM and GM. Within each habitat, the bars topped with different capital letters indicate significant difference between sampling months $(P<0.05)$ (Tukey's test).
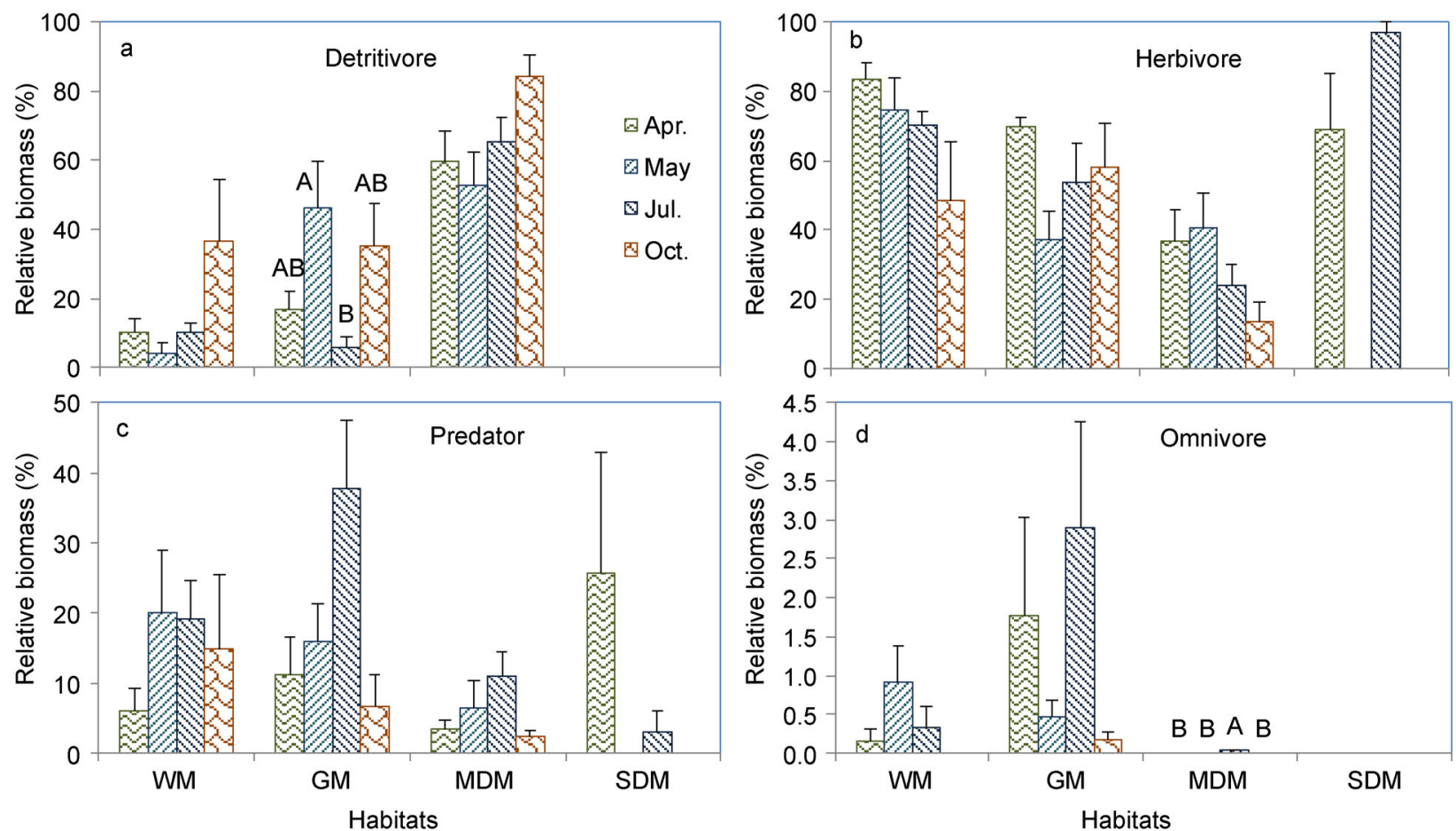

Fig. 5 The seasonal dynamics in the relative biomass of detritivores, herbivores, predators and omnivores for the WM, GM, MDM and SDM of the Qinghai-Tibetan Plateau (averaged over 3 years for each bar). Within each habitat, the bars topped with different capital letters indicate significant difference between sampling months $(P<0.05)$ (Tukey's test). 
Table 3 One-way ANOVA results for the effects of sampling month on the biomass and relative biomass of detritivores, herbivores, predators and omnivores in alpine wetlands on the Qinghai-Tibetan Plateau.

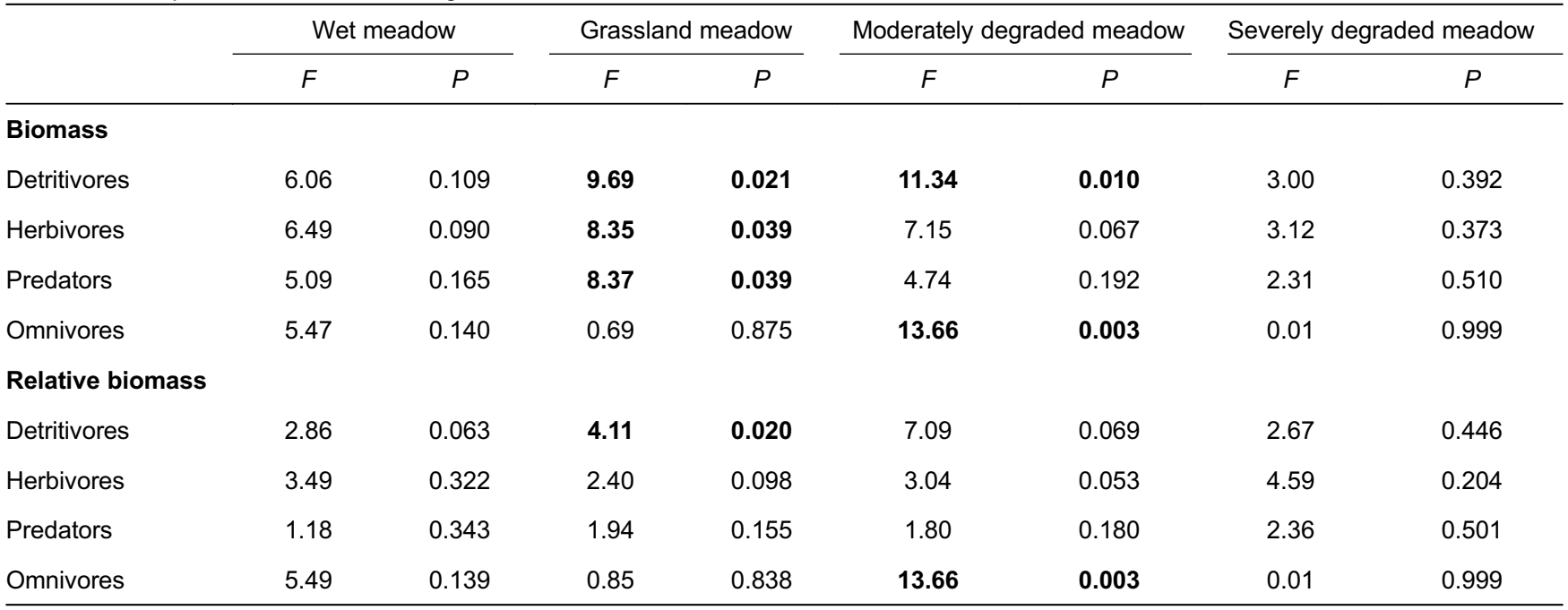

Note: Statistically significant $(P<0.05)$ results are shown in boldface.

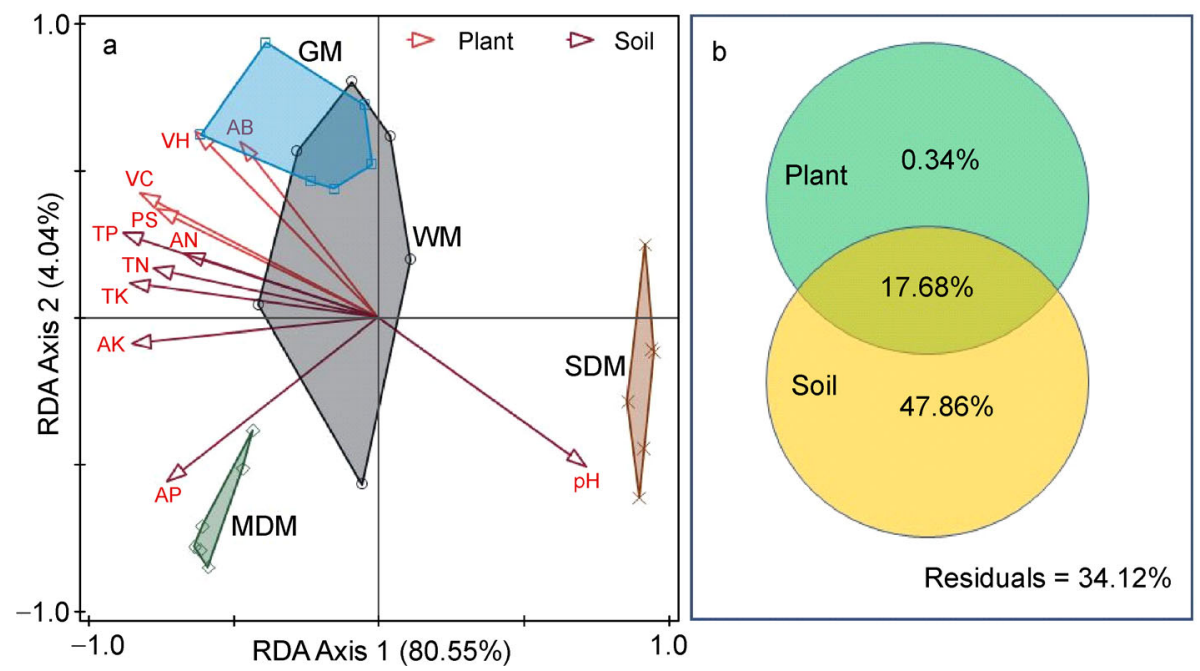

Fig. 6 Redundancy analysis ordination diagram for soil trophic structure (a) with variation partitioning analysis for the effects of plants and soil (b). The red arrows represent plant variables, and the rose arrows represent soil properties. Plant variables: SR, species richness; VC, vegetation coverage; $\mathrm{VH}$, vegetation height; $A B$, aboveground biomass; Soil variables: TN, total $N$; TK, total $K$; TP, total $P$; $A N$, available $N$; $\mathrm{AP}$, available $\mathrm{P}$; $\mathrm{AK}$, available $\mathrm{K}$; and $\mathrm{pH}, \mathrm{pH}$ value.

weaker in alpine wetlands than in some other ecosystems. The main reason might be that the average annual temperature $\left(1^{\circ} \mathrm{C}\right.$ in our study area) in alpine wetlands (above $3400 \mathrm{~m}$ elevation) is lower than that in some other ecosystems with lower elevations. Temperature is one of the main factors determining the abundance, and diversity of terrestrial invertebrates (Bokhorst et al., 2008).

4.2 Degradation effects on the trophic structure of soil macrofaunal community

The biomass of three trophic groups (detritivores, herbivores and predators) increased significantly, while the relative biomass increased for detritivores and remarkably decreased for herbivores and predators from WM to MDM, indicating that the biomass of the detritivores increases faster than those of herbivores and predators along the degradation stages. According to Table 1, the faster increase in detritivore biomass directly resulted from the dramatic increase in Polydesmida biomass in the MDM. Most Polydesmida individuals were also collected from MDM (Wu et al., 2015). However, the detritivores completely disappeared, although a few herbivore and predator individuals were still observed in SDM, illustrating that MDM is more suitable habitation for detritivores than for the other trophic groups. The reason may be that any change in other organisms would ultimately affect the food 
Table 4 The partial correlation coefficients of multiple regression analyses (stepwise procedure) between soil trophic groups and environmental factors.

\begin{tabular}{|c|c|c|c|c|}
\hline & $A B$ & BB & AP & AK \\
\hline \multicolumn{5}{|l|}{ Biomass } \\
\hline Total biomass & & & $0.838^{* * *}$ & \\
\hline Detritivores & & & $0.812^{\star \star \star}$ & \\
\hline Herbivores & & & $0.596^{\star *}$ & $0.436^{*}$ \\
\hline Predators & & & & $0.663^{* * *}$ \\
\hline Omnivores & $0.634^{\star * *}$ & & & \\
\hline \multicolumn{5}{|c|}{ Relative biomass } \\
\hline Detritivores & & & $0.602^{* *}$ & $0.755^{\star * *}$ \\
\hline Herbivores & & & & $-0.474^{*}$ \\
\hline Predators & & $0.697^{* * *}$ & & \\
\hline Omnivores & $0.714^{* * *}$ & & & \\
\hline
\end{tabular}

The superscript asterisks ${ }^{* * *},{ }^{* *}$ and ${ }^{*}$ indicate significant correlations at the $0.001,0.01$ and 0.05 levels, respectively. The environmental factors demonstrating no significant correlation with trophic groups were omitted automatically by IBM SPSS software. AB, aboveground biomass; BB, belowground biomass; AP, available P; AK, available K.

resources for detritivores but not for other trophic groups. Resource availability and quality has been regarded as a main bottom-up driver of the soil fauna community in terrestrial ecosystems (Cole et al., 2005; Salamon et al., 2006). In our study, the highest AP contents observed in MDM (Wu et al., 2015; Wu et al., 2017) provide sufficient and various foods for detritivores. Furthermore, AP, mainly derived from the decomposition and mineralization of organism bodies, has a positive and stronger effect on detritivores than on herbivores and predators (Table 4), with Polydesmida abundances also significantly correlated with AP and AK (Wu et al., 2015). The findings illustrated that the detritivores are more strongly affected by the degradation of alpine wetlands than herbivores. Hence our second hypothesis that the lower trophic levels responded more sensitively to the alpine wetland degradation than higher trophic levels of soil macrofauna was overturned by the findings.

Our finding that the detritivores, not the herbivores, respond more sensitively to the degradation of alpine wetlands was inconsistent with previous research, which found that the lower trophic level (herbivores) responds more sensitively to environmental changes than the higher levels (predators or omnivores) (Scherber et al., 2010). The first reason for this difference may be that our results were observed for biomass, but the results from the previous study were obtained for the individual abundances of each trophic group (Scherber et al., 2010). The second reason may be that our investigations were conducted in natural ecosystems with complicated changes in vegetation and soil properties, but the previous study was conducted in a manipulated ecosystem with only changes in plant species richness (Scherber et al., 2010). However, the main factors affecting the trophic structure were soil properties and not plant communities in alpine wetlands (Fig. 6b).

The relative biomass of herbivores and detritivores among habitats showed that the dominant trophic group of soil macrofauna communities transformed from herbivores in WM and GM to detritivores in MDM (Fig. 3a and b), indicating that the trophic structure of the soil macrofauna community switched during the degradation process. The RDA results further showed that the trophic structures of soil macrofauna in WM and GM were similar but differed clearly from those in MDM and SDM (Fig. 6a). Even within the same trophic group, the main taxa also changed between the habitats. For example, the dominant taxon for detritivores was Diptera larvae in WM and GM but Polydesmida in MDM (Table 1). This may result from the effects of environmental changes. Most parameters of the plant community and soil properties varied with no significance between WM and GM but differed significantly from MDM with the maximum contents of AP and AK observed in MDM (Wu et al., 2015; Wu et al., 2017). Moreover, the changes in most environmental factors, especially soil properties, had strong effects on the trophic groups and structure of soil macrofauna (Fig. 6a and b, Table 4). This demonstrated that the trophic structure of soil macrofauna is closely related to soil environmental factors and is specific to a certain degradation stage. Therefore, our third hypothesis that the trophic structure of soil macrofauna was specific to a certain degree of degradation was supported.

Another interesting finding needs to be mentioned. The changes in the trophic structure of soil macrofauna were determined by soil properties but not by plants (Fig. 6a and b, Table 4), suggesting that the variations in soil properties have 
important implications for the trophic structure of soil macrofauna in alpine wetlands. Regarding the trophic structure reflecting the material cycling path and energy utilization efficiency of ecosystems, we suggest that the trophic structure of soil macrofauna could be used as an indicator to evaluate the health of soil ecosystems. This is a supplement to existing methods of soil quality estimation (Bongers and Ferris, 1999; Ruf et al., 2003; Nuria et al., 2011).

Additionally, the changes in the trophic structure of soil macrofauna differed from those of soil nematodes in the same ecosystem, in which the trophic structure of soil nematodes was relatively stable among different habitats (Wu et al., 2017). The different responses between soil macrofauna and nematodes implied that the changes in belowground soil food webs are complex, and comprehensive studies are needed to reveal the degradation process of alpine wetlands.

4.3 Degradation effects on the seasonal dynamics of trophic structure

The seasonal dynamics of trophic structure were stronger in GM and MDM than in the other habitats. This finding suggests that alpine wetland degradation also affected the seasonality of the soil food web. The reason may be that some environmental factors, e.g., plant communities and soil properties, fluctuated more strongly with season in the GM and MDM than in the other habitats. The seasonal dynamics affected by temporal fluctuations in environmental factors were also observed for soil macrofauna in forest ecosystems (Wu et al., 2012; Wu and Wang, 2018) and soil nematodes in alpine wetlands (Wu et al., 2017) and other ecosystems (Stamou et al., 2005). In our study, the peat soil in WM was less sensitive to temperature changes than the sandy loam soil in the GM and MDM. In the severe degradation stage with lower plant coverage and limited food resources, few soil macrofauna can survive, although the environmental factors in the SDM changed dramatically over a duration of months. This may partly explain why the seasonal dynamics were relatively stable in the WM and SDM.

\section{Conclusions}

The biomasses for the community and the main trophic groups of detritivores, herbivores and predators of soil macrofauna increased significantly from the primary to moderately degraded alpine wetlands and decreased sharply to severely degraded alpine wetlands with most of the taxa disappearing. For the relative biomass, a similar change tendency was observed for detritivores, while the opposite response was detected for herbivores with fluctuation of predator. The dominant trophic group shifted from herbivores in primary alpine wetlands to detritivores in moderately degraded alpine wetlands. The seasonality of trophic structure also varied between the degradation stages. Soil properties were the main drivers affecting the trophic groups and trophic structure. Our results suggested that the detritivores responded more sensitively than the other trophic groups to the degradation of alpine wetlands and that the soil macrofaunal community had a habitat-specific trophic structure during the degradation process.

\section{Acknowledgments}

Hongzhi Zhang, Liwei Cui, Daxing Yang and Xianjin He took party in the fieldwork. Two anonymous reviewers helped to improve this manuscript. This work was supported by the National Natural Science Foundation of China (41971064, U20A2008 and 40801092) and the Second Tibetan Plateau Scientific Expedition and Research Program (2019QZKK0302).

\section{Electronic supplementary material}

Supplementary material is available in the online version of this article at https://doi.org/10.1007/s42832-021-0124-0 and is accessible for authorized users.

\section{References}

Bardgett, R.D., Chan, K.F., 1999. Experimental evidence that soil fauna enhance nutrient mineralization and plant nutrient uptake in montane grassland ecosystems. Soil Biology \& Biochemistry 31, 1007-1014.

Bardgett, R.D., Cook, R., 1998. Functional aspects of soil animal diversity in agricultural grasslands. Applied Soil Ecology 10, 263276.

Bardgett, R.D., Putten, W.H.V.D., 2014. Belowground biodiversity and ecosystem functioning. Nature 515, 505-511.

Bokhorst, S., Huiskes, A., Convey, P., Bodegom, P., Aerts, R., 2008. Climate change effects on soil arthropod communities from the Falkland Islands and the Maritime Antarctic. Soil Biology \& Biochemistry 40, 1547-1556

Bongers, T., Ferris, H., 1999. Nematode community structure as a bioindicator in environmental monitoring. Trends in Ecology \& Evolution 14, 224-228.

Bradford, M., Jones, T.H., Bardgett, R.D., Black, H.I., Boag, B., Bonkowski, M., Cook, R., Eggers, T., Gange, A., Grayston, S., Kandeler, E., McCaig, A.E., Newington, J.E., Prosser, J.I., Setälä, H., Staddon, P.L., Tordoff, G.M., Tscherko, D., Lawton, J.H., 2002. Impacts of soil faunal community composition on model grassland ecosystems. Science 298, 615-618.

Carrillo, Y., Ball, B.A., Bradford, M.A., Jordan, C.F., Molina, M., 2011. Soil fauna alter the effects of litter composition on nitrogen cycling in a mineral soil. Soil Biology \& Biochemistry 43, 1440-1449.

Cole, L., Bradford, M.A., Shaw, P.J., Bardgett, R.D., 2006. The abundance, richness and functional role of soil meso-and macrofauna in temperate grassland - A case study. Applied Soil Ecology 33, 186-198.

Cole, L., Buckland, S.M., Bardgett, R.D., 2005. Relating microarthropod community structure and diversity to soil fertility manipulations in temperate grassland. Soil Biology \& Biochemistry 37, 1707-1717. 
Colin, T., 1997. The intermediate disturbance hypothesis, refugia, and biodiversity in streams. Limnology and Oceanography 42, 938 949.

Cragg, R.G., Bardgett, R.D., 2001. How changes in soil faunal diversity and composition within a trophic group influence decomposition processes. Soil Biology \& Biochemistry 33, 2073 2081.

De Deyn, G.B., Raaijmakers, C.E., Zoomer, H.R., Berg, M.P., de Ruiter, P.C., Verhoef, H.A., Bezemer, T.M., van der Putten, W.H., 2003. Soil invertebrate fauna enhances grassland succession and diversity. Nature 422, 711-713.

Doblas-Miranda, E., Sánchez-Piñero, F., González-Megías, A., 2007. Soil macroinvertebrate fauna of a Mediterranean arid system: Composition and temporal changes in the assemblage. Soil Biology \& Biochemistry 39, 1916-1925.

Ehnes, R.B., Rall, B., Brose, U., 2011. Phylogenetic grouping, curvature and metabolic scaling in terrestrial invertebrates. Ecology Letters 14, 993-1000.

Ge, B., Zhang, D., Zhang, H., Li, Z., Liu, Z., Zhou, C., Tang, B., 2012. Community structure and functional groups of soil macrofauna in urban green spaces of Yancheng City, Jiangsu Province in spring. Chinese Journal of Ecology 31, 87-92.

Gu, Y., Bai, Y., Xiang, Q., Yu, X., Zhao, K., Zhang, X., Li, C., Liu, S., Chen, Q., 2018. Degradation shaped bacterial and archaeal communities with predictable taxa and their association patterns in Zoige wetland at Tibet plateau. Scientific Reports 8, 1-11.

Gunadi, B., Edwards, C.A., Arancon, N.Q., 2002. Changes in trophic structure of soil arthropods after the application of vermicomposts. European Journal of Soil Biology 38, 161-165.

He, C., Zhao, K., 1999. The conservation of wetlands biodiversities and their sustainable utilization in Roige Plateau. Journal of Natural Resources 14, 238-244.

Hodkinson, I.D., Jackson, J.K., 2005. Terrestrial and aquatic invertebrates as bioindicators for environmental monitoring, with particular reference to mountain ecosystems. Environmental Management 35, 649-666.

Huang, L., Zhang, X., 2008. Soil animal guilds and ecological distribution in forest ecosystems of the Northern $\mathrm{Da}$ Hinggan Mountains. Chinese Journal of Soil Science 39, 1017-1022.

Ineson, P., Leonard, M.A., Anderson, J.M., 1982. Effect of collembolan grazing upon nitrogen and cation leaching from decomposing leaf litter. Soil Biology \& Biochemistry 14, 601-605.

Ingham, R.E., Trofymow, J., Ingham, E.R., Coleman, D.C., 1985. Interactions of bacteria, fungi, and their nematode grazers: effects on nutrient cycling and plant growth. Ecological Monographs 55 , 119-140.

Koricheva, J., Mulder, C.P.H., Schmid, B., Joshi, J., Huss-Danell, K., 2000. Numerical responses of different trophic groups of invertebrates to manipulations of plant diversity in grasslands. Oecologia 125, 271-282.

Lam-Hoai, T., Rougier, C., Lasserre, G., 1997. Tintinnids and rotifers in a northern Mediterranean coastal lagoon. Structural diversity and function through biomass estimations. Marine Ecology Progress Series 152, 13-25.

Li, B., Dong, S., Jiang, X., Li, Z., 2008. Analysis on the driving factors of grassland desertification in Zoige wetland. Research of Soil \&
Water Conservation 15, 112-115.

Liao, C., 2009. Forest soil animal community ecology in south China tropical and subtropical zones. Guangzhou: Guangdong Science and Technology Press.

Liu, R., Zhao, H., Zhao, X., 2011a. Changes in functional groups of soil macro-faunal community in degraded sandy grassland under post - grazing natural restoration in Hoqin Sand Land. Ecology and Environment 20, 1794-1798.

Liu, R., Zhao, H., Zhao, X., 2011b. Desertification impact on macroinvertebrate diversity in grassland soil in Horqin, Northern China. Procedia Environmental Ences 10, 1401-1409.

Molino, J.F., Sabatier, D., 2001. Tree diversity in tropical rain forest: a validation of the intermediate disturbance hypothesis. Science 294, 1702-1704.

Nuria, R., Jérôme, M., Léonide, C., Christine, R., Gérard, H., Etienne, I., Patrick, L., 2011. IBQS: A synthetic index of soil quality based on soil macro-invertebrate communities. Soil Biology \& Biochemistry 43, 2032-2045.

Ruf, A., Beck, L., Dreher, P., Hund-Rinke, K., Römbke, J., Spelda, J., 2003. A biological classification concept for the assessment of soil quality: "biological soil classification scheme" (BBSK). Agriculture, Ecosystems \& Environment 98, 263-271.

Salamon, J.A., Alphei, J., Ruf, A., Schäfer, M., Scheu, S., Schneider, K., Sührig, A., Maraun, M., 2006. Transitory dynamic effects in the soil invertebrate community in a temperate deciduous forest: Effects of resource quality. Soil Biology \& Biochemistry 38, 209221.

Scherber, C., Eisenhauer, N., Weisser, W.W., Schmid, B., Voigt, W., Fischer, M., Schulze, E.D., Roscher, C., Weigelt, A., Allan, E., Beßler, H., Bonkowski, M., Buchmann, N., Buscot, F., Clement, L.W., Ebeling, A., Engels, C., Halle, S., Kertscher, I., Klein, A.M., Koller, R., König, S., Kowalski, E., Kummer, V., Kuu, A., Lange, M., Lauterbach, D., Middelhoff, C., Migunova, V.D., Milcu, A., Müller, R., Partsch, S., Petermann, J.S., Renker, C., Rottstock, T., Sabais, A., Scheu, S., Schumacher, J., Temperton, V.M., Tscharntke, T., 2010. Bottom-up effects of plant diversity on multitrophic interactions in a biodiversity experiment. Nature 468 , 553-556.

Scheu, S., Albers, D., Alphei, J., Buryn, R., Klages, U., Migge, S., Platner, C., Salamon, J., 2010. The soil fauna community in pure and mixed stands of beech and spruce of different age: trophic structure and structuring forces. Oikos 101, 225-238.

Scheu, S., Albers, D., Alphei, J., Buryn, R., Klages, U., Migge, S., Platner, C., Salamon, J.A., 2003. The soil fauna community in pure and mixed stands of beech and spruce of different age: trophic structure and structuring forces. Oikos 101, 225-238.

Setälä, H., 2002. Sensitivity of ecosystem functioning to changes in trophic structure, functional group composition and species diversity in belowground food webs. Ecological Research 17, 207-215.

Siemann, E., Haarstad, J., Tilman, D., 1999. Dynamics of plant and arthropod diversity during old field succession. Ecography 22, 406- 414.

Sommer, U., 1995. An experimental test of the intermediate disturbance hypothesis using cultures of marine phytoplankton. Limnology and Oceanography 40, 1271-1277. 
Stamou, G.P., Papatheodorou, E.M., Hovardas, A., Argyropoulou, M.D., 2005. Some structural and functional characteristics of a soil nematode community from a Mediterranean grassland. Belgian Journal of Zoology 135, 253.

Sun, H., 1996. Formation and evolution of Qinghai-Tibetan Plateau. Shanghai: Shanghai Science and Technology.

Tian, Y., Xiong, M., Song, G., 2005. Restoration succession of wetland soils and their changes of water and nutrient in Ruoergai Plateau. Chinese Journal of Ecology 24, 21-25.

Todd, T., James, S., Seastedt, T., 1992. Soil invertebrate and plant responses to mowing and carbofuran application in a North American tallgrass prairie. Plant and Soil 144, 117-124.

Wang, Q., Bao, W., Yan, Z., 2002. Basic types and characters of the western Zoige meadows and their changes in recent decades. Chinese Journal of Applied and Environmental Biology 8, 133141.

Wang, W., Dong, Z., Hu, G., Wei, Z., 2008. Analyses on change trend of sandy land in Zoige Plateau in last 30 years. Journal of Desert Research, 617-621.

Wardle, D.A., Yeates, G.W., Williamson, W., Bonner, K.I., 2003. The response of a three trophic level soil food web to the identity and diversity of plant species and functional groups. Oikos 102, 45-56.

Wei, X., Wu, P., 2021. Responses of soil insect communities to alpine wetland degradation on the eastern Qinghai-Tibetan Plateau, China. European Journal of Soil Biology 103, 103276.

Wu, P., Liu, S., Liu, X., 2012. Composition and spatio-temporal changes of soil macroinvertebrates in the biodiversity hotspot of northern Hengduanshan Mountains, China. Plant and Soil 357, 321-338.
Wu, P., Wang, C., 2018. Differences in spatiotemporal dynamics between soil macrofauna and mesofauna communities in forest ecosystems: The significance for soil fauna diversity monitoring. Geoderma 337, 266-272.

Wu, P., Zhang, H., Cui, L., Wickings, K., Fu, S., Wang, C., 2017. Impacts of alpine wetland degradation on the composition, diversity and trophic structure of soil nematodes on the QinghaiTibetan Plateau. Scientific Reports 7, 1-12.

Wu, P., Zhang, H., Wang, Y., 2015. The response of soil macroinvertebrates to alpine meadow degradation in the Qinghai-Tibetan Plateau, China. Applied Soil Ecology 90, 60-67.

Xiong, Y., Wu, P., Zhang, H., Cui, L., He, X., 2011. Dynamics of soil water conservation during the degradation process of the Zoige Alpine Wetland. Acta Ecologica Sinica 31, 5780-5788.

Yang, Y., Wang, S., 2001. Human disturbances on mire and peat soils in the Zoige Plateau. Natural Sciences 23, 37-41.

Yin, W., 1998. Pictorial keys to soil animals of China. Science Press, Beijing.

Zhang, S., Guo, H., Luo, Y., 2007. Assessment on driving force of climate change and livestock grazing capacity to grassland sanding in Ruoergai. Chinese Journal of Grassland 29, 64-71.

Zhang, X., Hou, W., Chen, P., 2001. Soil animal guilds and their ecological distribution in the northeast of China. Chinese Journal of Applied and Environmental Biology 7, 370-374.

Zhong, J., 1990. Larval Taxonomy. Agricultural Press, Beijing.

Zhou, H., Zhang, D., Zhang, J., Zhao, Y., Zhao, B., Wei, D., Zhang, J., 2017. Effects of canopy density on the functional group of soil macro fauna in Pinus massoniana plantations. Chinese Journal of Applied Ecology 28, 1860-1868. 